\title{
The Impact of the Affordable Care Act Medicaid Expansion on Racial/Ethnic and Sex Disparities in HIV Testing: National Findings from the Behavioral Risk Factor Surveillance System
}

\author{
Anitha Menon, MD, MPH ${ }^{1,2}{ }_{\mathbb{D}}$, Payal K. Patel, MD, MPH ${ }^{1,3,4,5}$, Monita Karmakar, PhD ${ }^{6}$, \\ and Renuka Tipirneni, MD, MSc ${ }^{1,5,6}$
}

\begin{abstract}
'University of Michigan Medical School, Ann Arbor, MI, USA; ${ }^{2}$ Department of Medicine, University of California, San Francisco, San Francisco, CA, USA; ${ }^{3}$ Division of Infectious Diseases, Department of Internal Medicine, VA Ann Arbor Healthcare System, Ann Arbor, MI, USA; ${ }^{4}$ Division of Infectious Diseases, Department of Internal Medicine, University of Michigan, Ann Arbor, MI, USA; ${ }^{5}$ University of Michigan Institute for Healthcare Policy and Innovation, Ann Arbor, MI, USA; 'Division of General Medicine, Department of Internal Medicine, University of Michigan, Ann Arbor, MI, USA.
\end{abstract}

\begin{abstract}
INTRODUCTION: Over half of Americans have not been tested for HIV in their lifetime, and over a third of all HIV diagnoses are made less than a year before progression to AIDS. The Affordable Care Act (ACA) Medicaid expansion of 2014 had potential to improve HIV and other health screenings. We assessed the differential impacts of Medicaid expansion on racial/ethnic and racial/ethnic-sex disparities in HIV testing.
\end{abstract}

METHODS: Using Behavioral Risk Factor Surveillance System data from all 50 states and D.C., we sampled low-income $(\leq 138 \%$ of the federal poverty level) adults ages 19-64 who were non-pregnant and non-disabled. Using a difference-in-differences (DD) and triple difference-in-differences (DDD) study design, we assessed differential impacts by race/ethnicity (White, Black, Hispanic, and other) and race/ethnicity-sex between 2011 and 2013 and 2014-2018. Outcomes were (1) ever having received an HIV test and (2) having received an HIV test in the last year.

RESULTS: Overall, Medicaid expansion was associated with a significant increase in HIV testing ( $p=0.003$ ). White females and Black males appeared most likely to benefit from this increase (DD 4.5 and 4.8 percentage points; $p=0.001$ and 0.130 respectively). However, despite having baseline higher rates of HIV diagnosis, Black and Hispanic females did not have increased rates of ever having HIV testing following Medicaid expansion (DD 1.9 and 0.9 percentage points; $p=0.391$ and 0.703 , respectively), including when compared to a White male reference subgroup and across other race/ethnicity-sex subgroups.

CONCLUSIONS: Medicaid expansion was associated with an increased overall probability of HIV testing among lowincome, nonelderly adults, but certain groups including Black females were not more likely to benefit from this increase, despite being disproportionately affected by HIV at baseline. Targeted and culturally informed interventions to increase Medicaid enrollment and access to

Prior Presentations This work has been previously presented at the Society of General Internal Medicine 2019 Annual Meeting (May 8-11, 2019; Washington, DC) and the AcademyHealth 2019 Annual Meeting (June 2-4. 2019: Washinaton. DC)

Received May 27, 2020

Accepted January 1, 2021

Published online January 26, 2021 primary care may be needed to expand HIV testing in vulnerable groups.

KEY WORDS: Medicaid; HIV; HIV testing; health disparities; health inequalities.

J Gen Intern Med 36(6):1605-12

DOI: $10.1007 / \mathrm{s} 11606-021-06590-2$

(C) Society of General Internal Medicine 2021

\section{INTRODUCTION}

An estimated 1.1 million people in the USA have HIV. Thirteen percent of these individuals are unaware of their status ${ }^{1}$ and approximately $40 \%$ of new HIV infections are transmitted by those with undiagnosed HIV. ${ }^{2}$ Unfortunately, over a third of HIV diagnoses are made less than a year before progression to AIDS. ${ }^{1}$ Individuals who do not initiate antiretroviral therapy (ART) until they have low CD4+ T cell (CD4) counts or an AIDS-defining illness are at higher risk for treatment failure and death. Centers for Disease Control and Prevention (CDC) recommendations call for routine HIV testing in all patients aged 13-64 at least once regardless of risk profile, unless the patient declines ("opt-out screening"), and annual screening for HIV in high-risk individuals and routine prenatal HIV screening in pregnant women. ${ }^{3}$

While HIV testing rates have increased since these recommendations were released, over half of Americans have not been tested for HIV in their lifetime. ${ }^{4}$ Though many HIV prevention programs focus on men who have sex with men, women account for $19 \%$ of new HIV infections and Black women make up $61 \%$ of new HIV infections in women. ${ }^{5}$ HIV incidence in Blacks and Latinos is 8 and 3 times as high as in Whites, respectively. The disparity is heightened for Black females and Hispanic females whose HIV incidence is 13.5 times and 3 times the incidence for White females, respectively. ${ }^{6,7}$ These groups also test later after initial HIV infection than Whites, which can increase HIV-related morbidity., 8 The multiple disadvantage model explains this disparity in part by positing that poor people-and in particular, women - of color may face cumulative disadvantages in 
HIV transmission, testing, and outcomes due to multiple socially stigmatized statuses when compared to singly disadvantaged or privileged groups. ${ }^{10}$ Earlier testing in these groups may lead to earlier linkage to care and narrow gender/race disparities in HIV outcomes. ${ }^{11}$

Recent CDC reports found the incidence of HIV has plateaued at 39,000 infections per year since 2013 and minorities remain disproportionately affected. ${ }^{12,13}$ These reports were released just after President Trump announced his plan to reduce new HIV diagnoses by $90 \%$ in the next 10 years, including efforts to increase HIV testing. ${ }^{14}$ The cause of low testing rates is multifactorial, but a major barrier to universal HIV testing is the absence of access to healthcare - including having a primary care provider (PCP) - among several vulnerable populations in the USA who may be at higher risk of HIV infection. ${ }^{15}$

Health insurance is a key driver of healthcare access, particularly preventive care. ${ }^{16,17}$ The 2014 Medicaid expansion to all nonelderly adults with household incomes of up to $138 \%$ of the Federal Poverty Level (FPL) was a landmark provision of the 2010 Affordable Care Act (ACA), expanding eligibility to childless, nonelderly, non-disabled adults. ${ }^{18}$ Since then, 38 states and Washington D.C. have expanded, ${ }^{19}$ and large insurance coverage gains have occurred among vulnerable populations in expansion states. ${ }^{20-23}$ Prior studies have demonstrated that increased access to care leads to an increase in diagnoses and consistent treatment for those with chronic conditions. ${ }^{24,25}$ Notably, Simon et al. demonstrated that utilization of preventive health services - including HIV screening - increased in states that expanded Medicaid. ${ }^{26,27}$ Preventive services are covered at no outof-pocket costs under the ACA, which may have further reduced barriers to screening. ${ }^{28}$

While this increase in HIV screening is encouraging, it is unclear whether high-risk groups benefited from increased testing proportionate to their risk. HIV screening rates were higher at baseline in Blacks and Latinos than in Asians, American Indians, and Whites, ${ }^{29}$ but the trajectory of these screening rates after the 2014 Medicaid expansion is unknown. These data are crucial in informing HIV prevention efforts that align with the CDC Division of HIV/AIDS Prevention (DHAP) Strategic Plan 2017-2020 goal of reducing HIV-related disparities and health inequities. ${ }^{13}$ In this study, we assessed changes in HIV testing rates in groups based on race/ethnicity and race/ethnicitysex before and after the 2014 ACA Medicaid expansion to further understand HIV testing disparities. Using the multiple disadvantage model as a theoretical framework, we hypothesized that, due to multiple socioeconomic disadvantages from low-income status, race/ethnicity, and sex, individuals from different groups would experience differential changes in HIV screening rates in states that expanded Medicaid under the ACA. ${ }^{10}$ We also hypothesized this may vary by whether the individual had a PCP, as healthcare providers must order HIV tests, so would be a potential key mediator of HIV screening.

\section{Population and Sample}

METHODS

We conducted a secondary analysis of Behavioral Risk Factor Surveillance System (BRFSS) data from all 50 states and the District of Columbia from 2011 to 2018. The BRFSS is a comprehensive nationally representative survey used to monitor health behaviors and healthcare use of US residents. BRFSS samples are representative of each state as well as the country. We restricted the BRFSS sample to the group targeted by Medicaid expansion: low-income (138\% of FPL or below), nonpregnant, and non-disabled adults under age 65 .

Income was estimated from categories of income and household size $(<1 \%$ missing in entire sample). The midpoint of the income range and number of household members were compared against FPLs for each year to estimate the federal poverty ratio for each respondent. Federal poverty ratios were then categorized as follows: $0-35.999 \%, 36-99.999 \%$, and $100-138 \%$. Respondents with estimated income above $138 \%$ of the federal poverty level were excluded.

\section{Measures}

Dependent Variables. The dependent variables were "pastyear HIV testing," defined as reporting having been tested for HIV in the 12 months prior to the interview and "ever HIV screening," defined as having ever been tested for HIV.

Time. To compare pooled periods before and after Medicaid expansion, we defined the pre period as 2011-2013 and the post period as 2014-2018.

Independent Variables. Expansion State Classification. We classified states that implemented Medicaid expansion by January 2018 as expansion states, as 2018 was the last year of available BRFSS data. Medicaid expansion became effective in January 2014 for all expansion states except for the following: Alaska (September 2015), Indiana (February 2015), Louisiana (July 2016), Michigan (April 2014), Montana (January 2016), New Hampshire (August 2014), and Pennsylvania (January 2015).

Though some states in the treatment group had expanded Medicaid to low-income adults prior to 2014, these states still experienced significant expansion in or after $2014 .^{26}$ Therefore, all 31 states and the District of Columbia that expanded Medicaid by January 2017 were included in our treatment group and all 19 non-expansion states were included in our control group (Appendix A1).

Race and Race-Sex Categories. Race was stratified into the following: non-Hispanic White, non-Hispanic Black, Hispanic, and non-Hispanic other. Race-sex was classified into the following: non-Hispanic White females, non-Hispanic White males, non-Hispanic Black males, non-Hispanic Black females, Hispanic males, Hispanic females, non-Hispanic other males, and non-Hispanic other females. 
Covariates. Covariates included age, sex, marital status, highest level of educational attainment, employment status, and whether the respondent was in the BRFSS cell phone sample.

\section{Statistical Analysis}

We first used a difference-in-differences (DD) approach to confirm the previously reported effect of ACA Medicaid Expansion on overall HIV testing rates. We then used a quasi-experimental triple difference-in-differences (DDD) approach to determine the differential effects of ACA Medicaid Expansion on HIV testing rates by race and race-sex.

We generated 2 dummy variables: expansion $=0$ if respondents were living in non-expansion states and expansion $=1$ if respondents were living in expansion states; time $=0$ if data were from 2011 to 2013 (the pre period) and time $=1$ if data were from 2014 to 2018 (the post period). DDD models were estimated with (1) race (categorical variable with 4 levels) and (2) race-sex (categorical variable with 8 levels) as the third interaction term in order to determine whether the Medicaid expansion effect sizes were equal across all demographic groups (e.g., if the policy effect was greater for Blacks vs. Whites). In the DDD equation below, race is a categorical indicator for either race or race-sex:

$y_{i j}=\beta_{0}+\beta_{1 j}$ Expansion $_{i}+\beta_{2 j}$ Time $_{i}+\beta_{3 j}$ Race $_{i k}+\beta_{4 j}$ Race $_{i k} \times$ Time $_{i}$

$+\beta_{5 j}$ Race $_{i k} \times$ Expansion $_{i}+\beta_{6 j}$ Time $_{i} \times$ Expansion $_{i}+\gamma j$ Race $_{i k}$

$\times$ Expansion $_{i} \times$ Time $_{i}+\xi X_{i}+\varepsilon_{i}$

where $y_{i j}$ is the $j$ th outcome for the $i$ th individual, $\gamma j$ is the triple difference (DDD) estimate, and $X_{i}$ is the covariates.

We used logistic regression to fit all models and estimated marginal predicted probabilities. Since we hypothesized that access to a PCP may modify the association between Medicaid expansion and HIV testing, data were stratified by whether respondents had a "personal doctor or healthcare provider" and re-analyzed.

We conducted sensitivity analyses by re-analyzing tripledifferences models for the "ever HIV tested" outcome variable after excluding states that expanded Medicaid eligibility before January 1, 2014. We also considered alternative analytic approaches, including an event study framework accounting for states expanding Medicaid in different years. To assess whether observed effects were related to the target group of the Medicaid expansion, we conducted a falsification test by repeating our analyses for adults 65 and older, who would not have been directly affected by the policy.

The parallel trends assumption was confirmed graphically (Fig. 1) and empirically with a Wald test that tested the null hypothesis that the difference in pre-2014 trends between expansion and non-expansion states was zero. We weighted all analyses appropriately for the BRFSS sampling design and included state and time (years) fixed effects. Two-tailed $p<0.05$ was considered statistically significant. We performed analyses with Stata version 16. Graphs were designed with RStudio version 1.1.463 and Microsoft Excel for Mac 2011 version 14.7.7.

\section{RESULTS}

Our sample included 306,461 (weighted $N=215,654,172$ ) low-income, non-pregnant, and nonelderly adults, including 179,425 (weighted $N=131,705,240$ ) individuals living in expansion states and 127,036 (weighted $N=83,948,932$ ) individuals living in non-expansion states. Individuals living in expansion states were more likely to be Hispanic or other race compared to those living in non-expansion states, but were otherwise demographically similar (Table 1). We also found non-Hispanic Whites were more likely to become insured and had lower rates of uninsurance both before and after Medicaid expansion than Black and Hispanic individuals (Appendix A3) (Table 2).

In seeking to replicate population findings from the Simon et al. paper, ${ }^{26}$ we found that during the period 2011-2018, Medicaid expansion was associated with a 2.4 percentage point increase in ever having received an HIV test $(p=$ 0.001). Rates of ever having had an HIV test differed by whether or not the respondent had a PCP. For those with a PCP, Medicaid expansion was associated with a 2.4 percentage point increase in ever having received an HIV test $(p=$ 0.016 ), and for those without a PCP this association was nonsignificant $(p=0.199)$. There was no significant association between Medicaid expansion and the change in probability of having received an HIV test in the last year (Table 3).

We next examined trends over time by race-sex. These estimates incorporate the BRFSS survey weights but are not adjusted for covariates. We found that absolute probabilities of HIV testing have decreased for Black and "other" females from 2011 to 2018 in both expansion and non-expansion states (Fig. 2).

In our triple difference-in-differences regressions, we found the overall increase in HIV testing following Medicaid expansion appeared to be driven by increases in HIV screening among non-Hispanic Whites-particularly White females (47\% pre-expansion and $49 \%$ post-expansion, $p=$ 0.001) - Black males, Hispanic males, and "other" females (Table 2 and Fig. 3). However, there were no significant differences in overall HIV testing after Medicaid expansion by race (White, Black, Hispanic, and other) or race-sex (Table 2). Despite having higher HIV diagnosis rates, Black and Hispanic females did not have increased rates of ever having HIV testing following Medicaid expansion (73\% and $52 \%$ pre-expansion and $70 \%$ and $51 \%$ post-expansion, respectively; $p=0.165$ and $p=0.703$ ), when compared to a White male reference subgroup (38\% pre-expansion and $40 \%$ postexpansion) and across other race/ethnicity-sex subgroups (Fig. 3 and Table 2).

In sensitivity analyses, we re-analyzed DDD models for the "ever having HIV test" outcome by dropping states that expanded Medicaid earlier than January 1, 2014. The DDD estimators for Black and Hispanic females were of higher magnitude in this analysis $(-4.1$ and -2.6 percentage points, respectively) but findings were otherwise similar, suggesting 
Trends in HIV Testing Rates, Expansion vs. Non-Expansion States

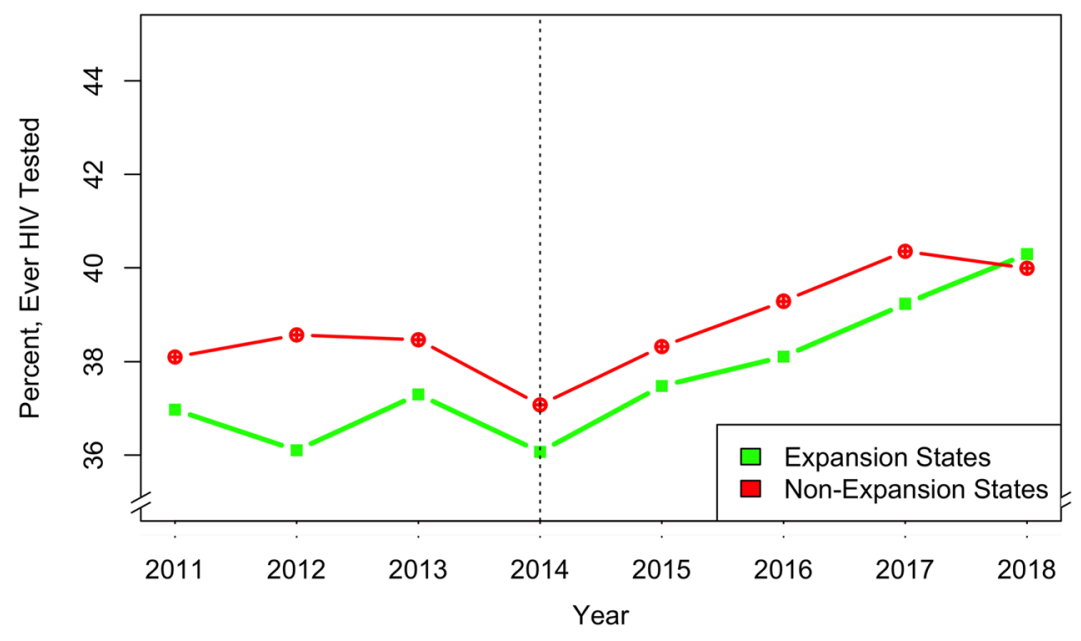

Figure 1 Overall trends in HIV testing rates, expansion vs. non-expansion states.

that our results are robust to the timing of Medicaid expansion. In our alternative event study framework, findings were largely similar but differed in which races and race-sex subgroups had statistically significant changes in HIV screening (Appendix A2). A falsification test repeating the main DDD analyses in adults 65 and older not directly affected by the policy showed null results, as expected.

\section{DISCUSSION}

This quasi-experimental analysis of the BRFSS from 2011 to 2018 found that the Affordable Care Act Medicaid expansion was associated with an increased probability of HIV testing among low-income, nonelderly adults, with approximately equally distributed gains among major race/ethnicity and race/ethnicity-sex subgroups. Though we did not find significant differences in HIV testing across race or race-sex categories following Medicaid expansion, this increased testing probability appears to be driven in part by gains in nonHispanic Whites, in particular White females, and Black males. Individual from other historically and multiply disadvantaged groups, however, including Black and Hispanic females were not more likely to benefit from increased HIV testing after Medicaid expansion, despite being disproportionately affected by HIV.

Black and Hispanic females may have been least likely to experience an increased probability of being tested for HIV following expansion, though these findings were not significant. Absolute rates of HIV testing for Black females also appear to be steadily decreasing in expansion and non-expansion states since 2011. This finding is concerning given that Hispanic and Black individuals - particularly women - are at-risk populations for new HIV diagnosis. ${ }^{7,30}$ While Blacks and Hispanics were 1.52 times more likely (Fig. 2) to have received an HIV test than Whites, they were 3-8 times more likely to contract HIV. ${ }^{31}$ These findings suggest widening racial disparities in HIV testing
Table 1 Characteristics of Low-Income ${ }^{a}$ Respondents in Medicaid Expansion and Non-expansion States

\begin{tabular}{|c|c|c|}
\hline Characteristics & $\begin{array}{l}\text { Non-expansion } \\
\text { states }(\text { observed }= \\
127,036 ; \text { weighted } \\
N=83,948,932) \\
\text { percent } \%\end{array}$ & $\begin{array}{l}\text { Expansion states } \\
\text { (observed }=179,425 ; \\
\text { weighted } N= \\
\text { 131,705,240) percent } \\
\%\end{array}$ \\
\hline \multicolumn{3}{|c|}{ Age category (years) } \\
\hline $18-24$ & 10.7 & 12.4 \\
\hline $25-44$ & 49.5 & 49.5 \\
\hline $45-64$ & 39.8 & 38.1 \\
\hline \multicolumn{3}{|l|}{$\begin{array}{l}\text { Sex } \\
\text { Sex }\end{array}$} \\
\hline Male & 44.7 & 45.0 \\
\hline Female & 55.3 & 55.0 \\
\hline \multicolumn{3}{|l|}{ Race } \\
\hline Non-Hispanic & 43.1 & 40.8 \\
\hline \multicolumn{3}{|l|}{ White } \\
\hline Non-Hispanic & 18.7 & 11.8 \\
\hline \multicolumn{3}{|l|}{ Black } \\
\hline Hispanic & 33.0 & 38.6 \\
\hline Other & 5.2 & 8.8 \\
\hline \multicolumn{3}{|l|}{ Race-sex } \\
\hline White male & 18.5 & 17.8 \\
\hline White female & 24.6 & 23.0 \\
\hline Black male & 7.6 & 5.1 \\
\hline Black female & 11.0 & 6.7 \\
\hline Hispanic male & 15.9 & 17.9 \\
\hline Hispanic female & 17.2 & 20.7 \\
\hline Other male & 2.6 & 4.2 \\
\hline Other female & 2.6 & 4.7 \\
\hline \multicolumn{3}{|l|}{ Percent FPL } \\
\hline$<36 \%$ & 14.8 & 17.8 \\
\hline $36-99 \%$ & 48.6 & 48.4 \\
\hline $100-138 \%$ & 36.6 & 33.8 \\
\hline \multicolumn{3}{|l|}{ Education level } \\
\hline High school or & 67.5 & 67.8 \\
\hline Greater than & 32.5 & 32.2 \\
\hline \multirow{2}{*}{\multicolumn{3}{|c|}{ high school }} \\
\hline & & \\
\hline $\begin{array}{l}\text { Married or } \\
\text { partnered }\end{array}$ & 70.9 & 67.1 \\
\hline $\begin{array}{l}\text { Not married or } \\
\text { partnered }\end{array}$ & 29.1 & 32.9 \\
\hline \multicolumn{3}{|l|}{ Employment status } \\
\hline Not employed & 61.8 & 61.6 \\
\hline Employed & 38.2 & 38.4 \\
\hline
\end{tabular}

${ }^{a}$ Low-income respondents eligible for Medicaid expansion are those with incomes $\leq 138 \%$ of the federal poverty level (FPL) 
Table 2 Percentage of Respondents in Medicaid Expansion and Non-expansion States Who Ever Received an HIV Test, Before and After 2014 Expansion

\begin{tabular}{|c|c|c|c|c|c|c|c|c|}
\hline & \multicolumn{8}{|c|}{ Percentage with HIV test (\%) $[95 \% \mathrm{CI}]^{\mathrm{a}}$} \\
\hline & \multicolumn{3}{|c|}{ Non-expansion states } & \multicolumn{5}{|c|}{ Expansion states } \\
\hline & Pre-Exp. & Post-Exp. & $\Delta^{\mathbf{b}}$ & Pre-Exp. & Post-Exp. & $\Delta^{\mathbf{b}}$ & $\mathrm{DiD}^{\mathrm{c}}$ & DDD $^{d}$ \\
\hline All & $50[49,50]$ & $48[47,49]$ & -1.5 & $47[46,48]$ & $48[47,49]$ & 0.9 & $2.4 * *$ & N/A \\
\hline PCP & $51[50,52]$ & $49[48,50]$ & -1.5 & $49[48,50]$ & $50[49,50]$ & 0.9 & $2.4 *$ & $\mathrm{~N} / \mathrm{A}$ \\
\hline No PCP & $48[46,50]$ & $46[45,48]$ & -1.6 & $43[42,45]$ & $44[42,45]$ & 0.2 & 1.8 & N/A \\
\hline \multicolumn{9}{|l|}{ Race } \\
\hline Non-Hisp. White & $46[45,47]$ & $45[44,46]$ & -0.9 & $43[42,44]$ & $45[44,46]$ & 2.3 & $3.2 * *$ & Ref \\
\hline Non-Hisp. Black & $65[63,67]$ & $64[62,66]$ & -1.4 & $71[69,73]$ & $71[69,73]$ & -0.4 & 1.0 & -2.1 \\
\hline Hispanic & $45[43,47]$ & $44[42,46]$ & -0.9 & $45[44,46]$ & $45[44,46]$ & 0.3 & 1.3 & -1.9 \\
\hline Other & $48[45,51]$ & $47[43,51]$ & -0.9 & $39[37,42]$ & $42[39,44]$ & 2.5 & 3.4 & 0.3 \\
\hline \multicolumn{9}{|l|}{ Race-sex } \\
\hline White male & $40[38,42]$ & $40[39,42]$ & 0.4 & $38[36,39]$ & $40[38,41]$ & 2.1 & 1.7 & Ref \\
\hline White female & $51[50,53]$ & $49[47,50]$ & -2.3 & $47[46,48]$ & $49[48,50]$ & 2.2 & $4.5^{* *}$ & 2.8 \\
\hline Black male & $62[59,65]$ & $60[57,64]$ & -1.7 & $68[65,71]$ & $71[69,74]$ & 3.1 & 4.8 & 3.1 \\
\hline Black female & $67[66,69]$ & $66[64,69]$ & -1.1 & $73[71,76]$ & $70[68,73]$ & -3.0 & -1.9 & -3.6 \\
\hline Hispanic male & $36[33,39]$ & $35[33,38]$ & -0.8 & $37[35,40]$ & $39[37,40]$ & 1.1 & 1.9 & 0.2 \\
\hline Hispanic female & $53[50,56]$ & $51[48,53]$ & -2.1 & $52[50,54]$ & $51[49,52]$ & -1.2 & 0.9 & -0.8 \\
\hline Other male & $42[37,48]$ & $46[40,51]$ & 3.2 & $38[34,42]$ & $40[36,44]$ & 1.5 & -1.7 & -3.4 \\
\hline Other female & $53[49,57]$ & $49[44,54]$ & -4.2 & $40[37,44]$ & $43[40,47]$ & 3.4 & 7.6 & 5.8 \\
\hline
\end{tabular}

${ }^{a}$ Regression-adjusted and survey-weighted predicted proportions. Covariates were age, sex, marital status, highest level of educational attainment, employment status, and whether the respondent was in the BRFSS cell phone sample. ${ }^{b}$ All absolute testing rates are rounded to the nearest percentage point; deltas are rounded to the nearest tenth percentage point. ${ }^{c}$ Difference-in-differences compared within race or race-sex subgroup. ${ }^{d}$ Triple difference-in-differences compared to reference group. *Significant at $p<0.05$; **significant at $p<0.01$

rates relative to baseline risk. "Other" males were also less likely than White males to experience an increased probability of being tested for HIV following expansion, though the heterogeneity in this group makes interpreting drivers of this increase difficult.

Among individuals with access to a PCP, Medicaid expansion was associated with a 2.4 percentage point increase in the probability of HIV testing. However, there was no association between Medicaid expansion and increase in HIV testing rates among individuals who did not have a PCP. Increases in access to and reduced cost sharing for preventive care likely contributed in part to increased HIV testing rates. As evidencebased preventive services are exempt from cost sharing under the ACA, people may have experienced fewer barriers to screening, including possible exemption from copays for PCP visits and lab testing. Our finding that individuals with access to a PCP were more likely to have had HIV screening after Medicaid expansion supports this.

Racial/ethnic groups experienced varying gains in health insurance coverage as a result of the ACA Medicaid Expansions. We found health insurance coverage increased most for

Table 3 Percentage of Respondents in Medicaid Expansion and Non-Expansion States Who Received an HIV Test in the Last Year, Before and After 2014 Expansion

\begin{tabular}{|c|c|c|c|c|c|c|c|c|c|c|c|c|}
\hline \multirow[b]{4}{*}{ All } & \multicolumn{12}{|c|}{ Percentage with HIV testing the last year $(\%)[95 \% \mathrm{CI}]^{\mathrm{a}}$} \\
\hline & \multicolumn{5}{|c|}{ Non-expansion states } & \multicolumn{7}{|c|}{ Expansion states } \\
\hline & \multicolumn{2}{|c|}{ Pre-Exp. } & \multicolumn{2}{|c|}{ Post-Exp. } & \multirow{2}{*}{$\frac{\Delta^{\mathbf{b}}}{-0.7}$} & \multicolumn{2}{|c|}{ Pre-Exp. } & \multicolumn{2}{|c|}{ Post-Exp. } & \multirow{2}{*}{$\frac{\Delta^{\mathbf{b}}}{-0.3}$} & \multirow{2}{*}{$\frac{\mathbf{D i D}^{\mathbf{c}}}{0.4}$} & \multirow{2}{*}{$\frac{\text { DDD }^{\mathbf{d}}}{\text { N/A }}$} \\
\hline & 18 & {$[17,18]$} & 17 & {$[16,18]$} & & 18 & {$[17,19]$} & 18 & {$[17,18]$} & & & \\
\hline PCP & 19 & {$[18,20]$} & 18 & {$[17,19]$} & -0.8 & 19 & {$[19,20]$} & 19 & {$[18,19]$} & -0.7 & 0.1 & N/A \\
\hline No PCP & 16 & {$[15,17]$} & 15 & {$[14,17]$} & -0.5 & 16 & {$[15,17]$} & 16 & {$[14,17]$} & 0.1 & 0.6 & N/A \\
\hline \multicolumn{13}{|l|}{ Race } \\
\hline Non-Hisp. White & 12 & {$[12,13]$} & 12 & {$[11,13]$} & -0.1 & 12 & {$[12,13]$} & 13 & {$[36,37]$} & 0.5 & 0.6 & Ref \\
\hline Non-Hisp. Black & 33 & {$[31,35]$} & 31 & {$[29,33]$} & -1.5 & 38 & {$[36,40]$} & 37 & {$[59,63]$} & -1.3 & 0.2 & -0.4 \\
\hline Hispanic & 16 & {$[14,17]$} & 15 & {$[14,17]$} & -0.1 & 19 & {$[18,20]$} & 18 & {$[42,44]$} & -1.0 & -0.9 & -1.5 \\
\hline Other & 18 & {$[15,20]$} & 15 & {$[12,17]$} & -3.1 & 13 & {$[12,15]$} & 15 & {$[35,40]$} & 1.5 & 4.6 & 4.0 \\
\hline \multicolumn{13}{|l|}{ Race-sex } \\
\hline White male & 11 & {$[10,13]$} & 11 & {$[10,13]$} & 0.1 & 12 & {$[11,13]$} & 12 & {$[11,13]$} & 0.1 & 0.1 & Ref \\
\hline White female & 13 & {$[12,14]$} & 13 & {$[38,40]$} & -0.2 & 13 & {$[12,14]$} & 13 & {$[12,14]$} & 0.8 & 1.0 & 0.9 \\
\hline Black male & 30 & {$[27,33]$} & 26 & {$[23,30]$} & -3.5 & 40 & {$[38,43]$} & 36 & {$[33,39]$} & -4.0 & -0.4 & -0.5 \\
\hline Black female & 35 & {$[33,37]$} & 34 & {$[32,37]$} & -0.3 & 63 & {$[61,65]$} & 59 & {$[57,61]$} & -4.0 & -3.7 & -3.8 \\
\hline Hispanic male & 12 & {$[10,14]$} & 10 & {$[8,12]$} & -1.8 & 15 & {$[14,17]$} & 15 & {$[13,17]$} & -0.2 & 1.6 & 1.5 \\
\hline Hispanic female & 19 & {$[17,21]$} & 20 & {$[18,22]$} & 0.9 & 22 & {$[21,24]$} & 20 & {$[19,22]$} & -2.1 & -3.0 & -3.1 \\
\hline Other male & 15 & {$[11,19]$} & 12 & {$[9,15]$} & -3.5 & 12 & {$[10,15]$} & 13 & {$[10,15]$} & 0.5 & 4.0 & 3.9 \\
\hline Other female & 20 & {$[17,23]$} & 18 & {$[13,22]$} & -2.2 & 14 & {$[12,17]$} & 17 & {$[14,20]$} & 2.2 & 4.4 & 4.4 \\
\hline
\end{tabular}

${ }^{a}$ Regression-adjusted and survey-weighted predicted proportions. Covariates were age, sex, marital status, highest level of educational attainment, employment status, and whether the respondent was in the BRFSS cell phone sample. ${ }^{b}$ All absolute testing rates are rounded to the nearest percentage point; deltas are rounded to the nearest tenth percentage point. ${ }^{c}$ Difference-in-differences compared within race or race-sex subgroup. ${ }^{d}$ Triple difference-in-differences compared to reference group. *Significant at $p<0.05$; **significant at $p<0.01$ 

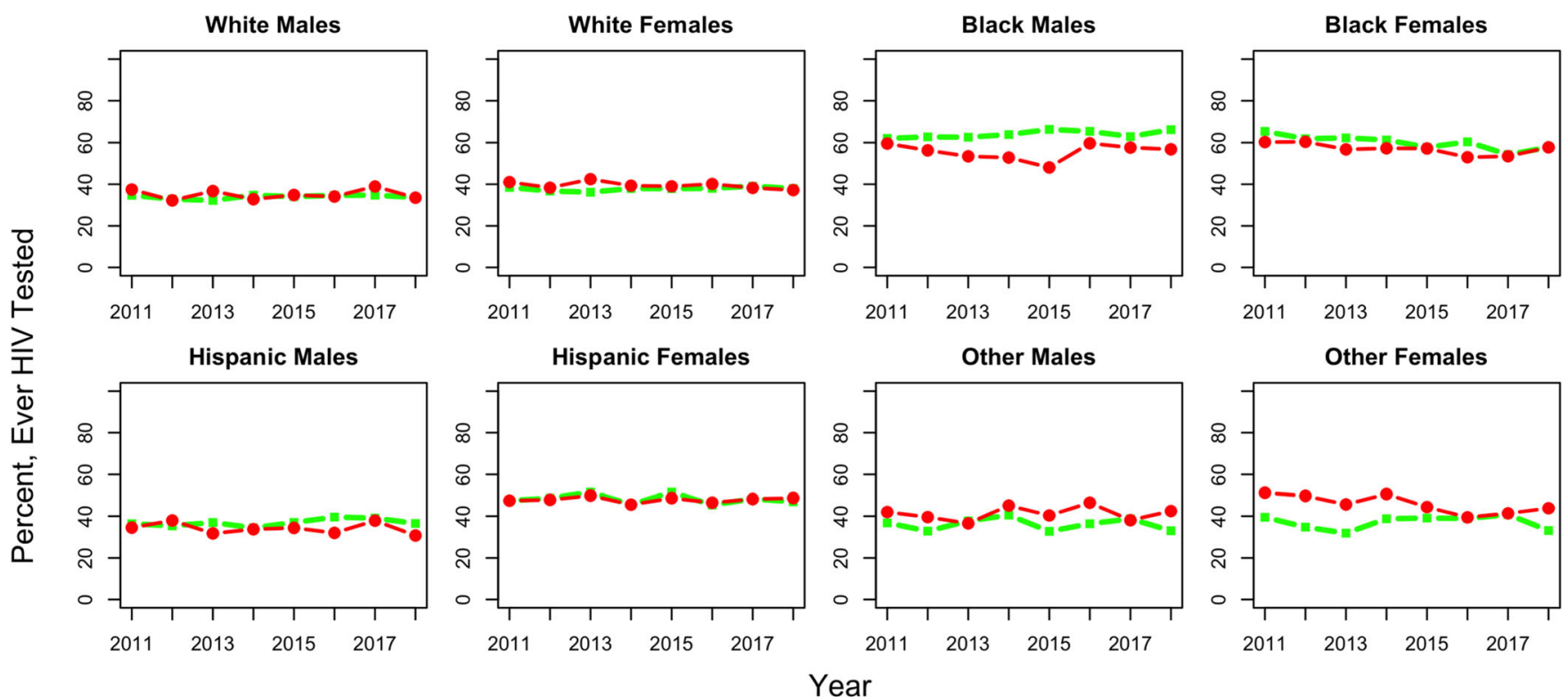

Year

$\square$ Expansion States

$\square$ Non-Expansion States

Figure 2 Trends in HIV testing rates by race/ethnicity-sex category (2011-2018).

non-Hispanic White individuals, while rates of uninsurance remained higher for Black and Hispanic individuals both before and after Medicaid expansion. ${ }^{32}$ Moreover, Black females, Hispanic females, and "Other" males were less likely to gain coverage after Medicaid expansion than White males and females. These are the same groups that were less likely to experience an increased probability of HIV testing, suggesting that the relative lack of increased coverage in minority groups may have contributed to lack of gains in HIV testing. ${ }^{32}$

Medicaid expansion was associated with an increased probability of HIV testing in individuals with access to a PCP. The
ACA led to significant increases in access to health insurance, healthcare, and preventive care overall and in low-income populations. $^{26,33,34}$ Previous work has shown that vulnerable populations like young adults and racial/ethnic minorities also experienced gains in coverage $\mathrm{e}^{35,36}$ and reduction in disparities in coverage and access to care. ${ }^{37,38}$ The present study's analysis confirms increasing coverage rates among racial/ethnic minorities after Medicaid expansion. This underscores the importance of expanding Medicaid in more states and connecting Medicaid beneficiaries to primary care in states that have already expanded.

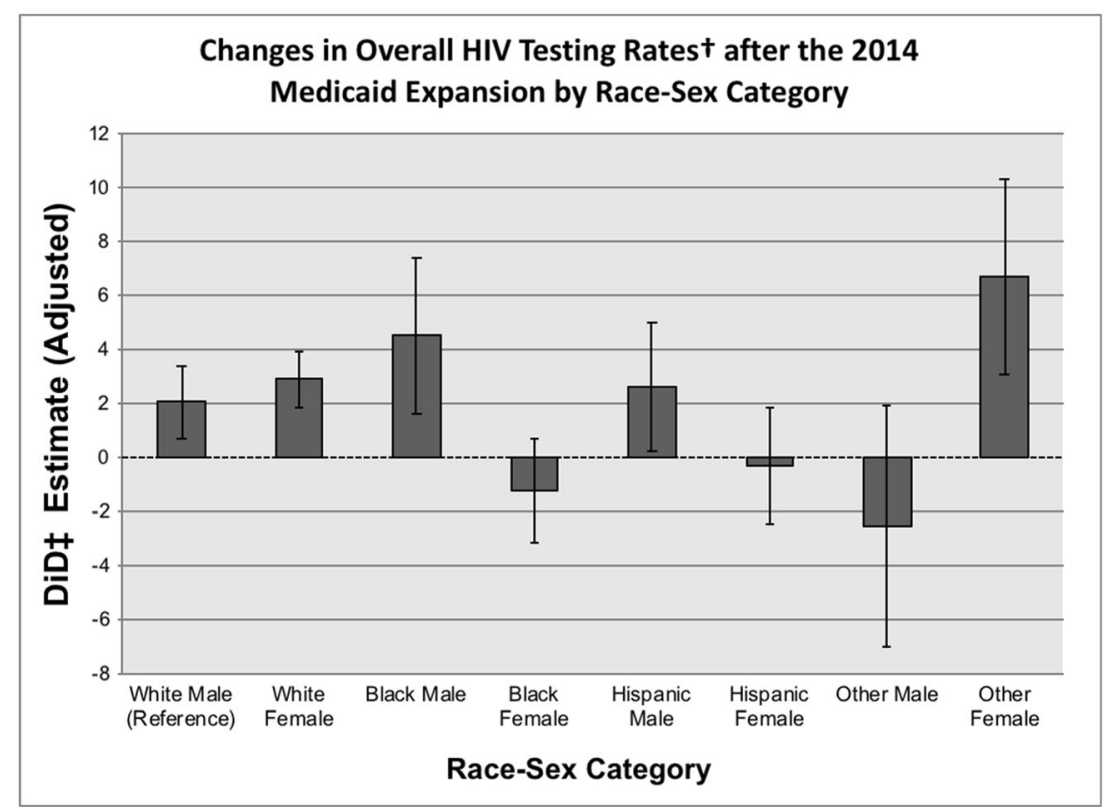

Figure 3 Changes in HIV testing rates after the 2014 Medicaid Expansion by race-sex category. 
Our finding that Black and Hispanic females-groups least likely to experience an increased probability of HIV testing after expansion-were also least likely to become insured after expansion emphasizes the importance of increasing Medicaid enrollment in expansion states through culturally informed outreach and assistance. It also calls for other approaches to provide insurance for minorities who remain ineligible for Medicaid, including recent immigrants and undocumented immigrants. ${ }^{39}$ Continued attention to these groups is needed to accomplish the national goal of reducing HIV incidence by $90 \%$ in the next 10 years or the CDC Strategic Plan goal of reducing HIV-related disparities and inequities.

Our analysis has several limitations. The BRFSS sampling and weighting algorithm changed in 2011, so we limited pre-expansion data to 3 years. Individuals interviewed early in 2014 were exposed to expansion for less time than those interviewed later that year or in subsequent years, potentially leading to underestimation of the treatment effect of Medicaid expansion. We also included recent expansion states in the treatment group (e.g., Montana, Louisiana), which, as suggested by sensitivity analyses, may have biased our results towards the null. Given the serial cross-sectional design of the BRFSS, those who had a PCP after the Medicaid expansion may have differed from before the expansion, as more individuals gained access to a PCP; however, we considered PCPs an important factor on the pathway from coverage to HIV screening so presented stratified analyses accordingly. We also acknowledge limitations of the "other" race category, which is heterogeneous but considered as such in our analyses due to sample size limitations. Finally, BRFSS did not collect sexual orientation data until 2014, so we were unable to determine the impact of expansion on other key groups disproportionately affected by HIV .

\section{CONCLUSIONS}

The Affordable Care Act Medicaid expansion was associated with an increased overall probability of HIV testing among lowincome, nonelderly adults in most race/ethnicity and sex subgroups. However, Black and Hispanic females were not more likely to benefit from this increase, despite being disproportionately affected by HIV at baseline. Culturally targeted interventions to increase Medicaid enrollment and primary care access - in addition to Medicaid expansion in more states - are needed to expand HIV testing in vulnerable groups.

Corresponding Author: Anitha Menon, MD, MPH; Department of Medicine, University of California, San Francisco, San Francisco, CA, USA (e-mail: Anitha.Menon@ucsf.edu).

Supplementary Information The online version contains supplementary material available at https://doi.org/10.1007/s11606-02106590-2.
Author Contributions Anitha Menon led the design of this study, coled the data analyses, and wrote and edited the manuscript; Payal Patel contributed to study design and edited the manuscript; Monita Karmakar co-led the data analyses and provided statistical guidance; Renuka Tipirneni supervised the study design and edited the manuscript.

\section{Compliance with Ethical Standards:}

Conflict of Interest: The authors declare that they do not have a conflict of interest.

\section{REFERENCES}

1. CDC FACT SHEET: HIV Testing in the United States. In: CDC, editor. 2016.

2. Gopalappa C, Farnham PG, Chen YH, Sansom SL. Progression and Transmission of HIV/AIDS (PATH 2.0). Med Decis Mak 2017;37(2):22433.

3. Branson BM, Handsfield HH, Lampe MA, Janssen RS, Taylor AW, Lyss SB, et al. Revised recommendations for HIV testing of adults, adolescents, and pregnant women in health-care settings. Morb Mortal Wkly Rep Recomm Rep. 2006;55(14):1-CE-4.

4. CDC. Behavioral Risk Factor Surveillance System Survey Questionnaire. Atlanta, Georgia: U.S. Department of Health and Human Services. 2016.

5. Hess KL, Johnson SD, Hu X, Li J, Wu B, Yu C, et al. Diagnoses of HIV infection in the United States and dependent areas, 2017. 2018.

6. Johnson AS, Hess KL, Hu S, Li J, Zhu H, Yu C, et al. Monitoring selected national HIV prevention and care objectives by using HIV surveillance data: United States and 6 dependent areas, 2016. 2018.

7. Centers for Disease Control and Prevention. HIV among Latinos. CDC Fact Sheet 2019.

8. Chen NE, Gallant JE, Page KR. A systematic review of HIV/AIDS survival and delayed diagnosis among Hispanics in the United States. J Immigr Minor Health 2012;14(1):65-81.

9. Valdiserri RO, Holtgrave $\mathbf{D R}$, West GR. Promoting early HIV diagnosis and entry into care. Aids. 1999;13(17):2317-30.

10. Grollman EA. Multiple disadvantaged statuses and health: the role of multiple forms of discrimination. J Health Soc Behav 2014;55(1):3-19.

11. McCree DH, Sutton M, Bradley E, Harris N. Changes in the disparity of HIV diagnosis rates among black women-United States, 2010-2014. MMWR Morb Mortal Wkly Rep 2017;66(4):104.

12. Centers for Disease Control and Prevention. CDC data confirm: Progress in HIV prevention has stalled. 2019

13. Centers for Disease Control and Prevention. CDC HIV Prevention Progress Report,. 2019 October 1, 2019. Report No.

14. U.S Department of Health and Human Services. Statement on FY2020 Budget Proposal for Ending The HIV Epidemic In America. 2019.

15. Wagner $\mathbf{J}, \mathbf{W u} \mathbf{Y}$, Sood $\mathbf{N}$. The Affordable Care Act May Increase The Number Of People Getting Tested For HIV By Nearly 500,000 By 2017. Health Aff 2014;33(3):378-85.

16. World Health Organization. The World Health Report 2010: Health Systems Financing: the Path to Universal Coverage: World health organization (WHO); 2010.

17. Institute of Medicine Committee on the Consequences of Uninsurance. Care without coverage: Too little, too late: National Academy Press; 2002.

18. Overview of the Affordable Care Act and Medicaid. Medicaid and CHIP Payment and Access Commission; 2018; Available from: https://www.kff. org/health-reform/fact-sheet/summary-of-the-affordable-care-act/. Accessed 20 July 2018.

19. Status of State Action on the Medicaid Expansion Decision. The Kaiser Family Foundation; Available from: https://www.kff.org/health-reform/state-indicator/ state-activity-around-expanding-medicaid-under-the-affordable-care-act/? currentTimeframe $=0 \&$ sortModel $=\% 7 \mathrm{~B} \% 22$ colld $\% 22: \% 22$ Location $\% 22, \% 22$ sort\%22:\%22asc\%22\%7D-note-9. Accessed 18 May 2019.

20. Wehby GL, Lyu w. The Impact of the ACA Medicaid Expansions on Health Insurance Coverage through 2015 and Coverage Disparities by Age, Race/Ethnicity, and Gender. Health Serv Res 2018;53(2):1248-71.

21. Buchmueller TC, Levinson ZM, Levy HG, Wolfe BL. Effect of the Affordable Care Act on Racial and Ethnic Disparities in Health Insurance Coverage. Am J Public Health 2016; 106(8): 1416-21. 
22. Griffith K, Evans L, Bor J. The Affordable Care Act Reduced Socioeconomic Disparities In Health Care Access. Health Aff. 2017.

23. Hayes SL, Riley P, Radley DC, McCarthy D. Reducing Racial and Ethnic Disparities in Access to Care: Has the Affordable Care Act Made a Difference? Issue brief (Commonwealth Fund). 2017 Aug;2017:1-14.

24. Antonisse L, Garfield R, Rudowitz R, Rtiga $\mathbf{S}$. The Effects of Medicaid Expansion under the ACA: Updated Findings from a Literature Review. The Henry J. Kaiser Family Foundation; 2018 [cited 2018 June 16].

25. Wherry LR, Miller S. Early Coverage, Access, Utilization, and Health Effects Associated With the Affordable Care Act Medicaid Expansions: A Quasi-experimental Study. Ann Intern Med 2016;164(12):795-803.

26. Simon K, Soni A, Cawley J. The Impact of Health Insurance on Preventive Care and Health Behaviors: Evidence from the First Two Years of the ACA Medicaid Expansions. J Policy Anal Manag 2017;36(2):390417.

27. Cawley J, Soni A, Simon K. Third year of survey data shows continuing benefits of Medicaid expansions for low-income childless adults in the US. J Gen Intern Med 2018;33(9):1495-7.

28. The Patient Protection and Affordable Care Act, Pub. L. No. 111148(2010).

29. Gaines TL, Caldwell JT, Ford CL, Mulatu MS, Godette DC. Relationship between a Centers for Disease Control and Prevention expanded HIV testing initiative and past-year testing by race/ethnicity: a multilevel analysis of the Behavioral Risk Factor Surveillance System. AIDS Care 2016;28(5):554-60.

30. Centers for Disease Control and Prevention. HIV in the United States and Dependent Areas. 2018.

31. Lo CC, Runnels RC, Cheng TC. Racial/ethnic differences in HIV testing: An application of the health services utilization model. SAGE Open Med 2018;6:2050312118783414.

32. Yue D, Rasmussen PW, Ponce NA. Racial/Ethnic Differential Effects of Medicaid Expansion on Health Care Access. Health Serv Res 201822.

33. Miller S, Wherry LR. Health and Access to Care during the First 2 Years of the ACA Medicaid Expansions. N Engl J Med. 2017 2017/03/ 09;376(10):947-56.

34. Blavin F, Karpman M, Kenney GM, Sommers BD. Medicaid Versus Marketplace Coverage For Near-Poor Adults: Effects On Out-Of-Pocket Spending And Coverage. Health Aff. 2018 2018/02/01;37(2):299-307.

35. McMorrow S, Kenney GM, Long SK, Anderson N. Uninsurance Among Young Adults Continues To Decline, Particularly In Medicaid Expansion States. Health Aff. 2015 2015/04/01;34(4):616-20.

36. Johnston EM, Strahan AE, Joski P, Dunlop AL, Adams EK. Impacts of the Affordable Care Act's Medicaid Expansion on Women of Reproductive Age: Differences by Parental Status and State Policies. Womens Health Issues 2018;28(2):122-9.

37. Buchmueller TC, Levy HG. The ACA's Impact On Racial And Ethnic Disparities In Health Insurance Coverage And Access To Care: An examination of how the insurance coverage expansions of the Affordable Care Act have affected disparities related to race and ethnicity. Health Aff 2020;39(3):395-402.

38. Griffith KN, Jones DK, Bor JH, Sommers BD. Changes In Health Insurance Coverage, Access To Care, And Income-Based Disparities Among US Adults, 2011-17: Assessing access to care among US nonelderly adults before and after Trump administration policies that may have affected the Affordable Care Act's effectiveness. Health Aff 2020;39(2):319-26.

39. Artiga S, Orgera K, Damico A. Changes in Health Coverage by Race and Ethnicity since the ACA, 2010-2018. San Francisco: Kaiser Family Foundation; 2020. https://www.kff.org/disparities-policy/issue-brief/ changes-in-health-coverage-by-race-and-ethnicitysince-the-aca-20102018. Accessed 10 May 2019.

Publisher's Note: Springer Nature remains neutral with regard to jurisdictional claims in published maps and institutional affiliations. 